He had stumbled over two steps and developed an effusion. His knee had given way several times since the injury. On examination a small effusion was still present. Both collateral ligaments were stable. The anterior drawer test was negative but Lachmann's test was positive. On direct questioning he admitted taking anabolic steroids. He had just completed 'an eight week course' of oxymethalone, taking $50 \mathrm{mg}$ four times a day during this period.

Six weeks later he was admitted for an arthroscopy. On examination under anaesthetic both collaterals were intact, and his anterior drawer and Lachmann's test were both positive on this occasion. Arthroscopy showed a complete rupture of the anterior cruciate ligament with intercondylar synovitis. The patient was informed of the diagnosis. He was treated conservatively with physiotherapy. At follow up one year later the patient had changed his lifestyle significantly, he denied any further anabolic steroid misuse. He complained occasionally of giving way but was not keen to progress to an autologous anterior cruciate ligament repair.

\section{Discussion}

Anabolic steroid abuse is now receiving greater media attention. Perry et al. ${ }^{1}$ have shown prevalence rates of over $35 \%$ in certain gymnasia. Korkia and Stimson ${ }^{2}$ have found that $9 \%$ of men and $2 \%$ of women in their particular study cohort have used anabolic steroids at some time. With the widespread use of such drugs the incidence of complications is expected to increase.

There are numerous papers linking tendon rupture with misuse of anabolic steroids. For example Hill et al. ${ }^{3}$ describe a spontaneous rupture of the quadriceps tendon in an athlete following such drug abuse, Kramhoft and Solgaard ${ }^{4}$ report on the rupture of the extensor pollicis longus tendon, and both Bach et al. ${ }^{5}$ and Herrick and Herrick ${ }^{6}$ independently report triceps rupture in weight lifters using steroids.

There are many theories about the mechanism of rupture. The increase in muscle power observed in some individuals is not matched by an increase in the tendon strength, thereby predisposing to rupture. Among lifters the two structures that tend to rupture are the biceps tendon and the quadriceps. Others have suggested that steroid induced aggression may cause individuals to overtrain. Normal signals telling the athlete to stop maybe overridden by the steroids, resulting in injury. Finally, Laseter and Russell ${ }^{7}$ suggest that anabolic steroid use combined with exercise may lead to dysplasia of collagen fibrils, which can decrease the tensile strength of the tendon. Wood et al. ${ }^{8}$ have shown changes in crimp morphology of rat tendons exposed to exercise and anabolic steroids. These changes may alter the rupturing strain of tendons.

We believe this case report supports the theory that the combination of exercise and anabolic steroids results in human connective tissue disruption. It is the first case report linking ligament rupture with systemic use of anabolic steroids.

\section{Acknowledgements}

The authors would like to thank Michele Verroken of the Sports Council and Lesley Harrison of the National Sports Medicine Institute.

\section{References}

1 Perry HM, Wright D, Littlepage BNC. Dying to be big: a review of anabolic steroids. Br J Sports Med 1992; 26: 259-61.

2 Korkia P, Stimson GV. Anabolic steroid use in Great Britain. London The Centre for Research on Drugs and Health Behaviour, 1993.

3 Hill JA, Suker JR, Sachs K, Brigham C. The athletic polydrug abuse phenomenon. A case report. Am J Sports Med 1983; 11: 269-71.

4 Kramhoft M, Solgaard S. Spontaneous rupture of the extensor pollicis longus tendon after anabolic steroids. J Hand Surg 1986; 11 87.

5 Bach BR, Warren RF, Wickiewicz TL. Triceps rupture: a case report and literature review. Am J Sports Med 1987; 15 : 285-9.

6 Herrick RT, Herrick S. Ruptured triceps in a powerlifter presenting as a cubital tunnel syndrome: a case report. Am J Sports Med 1987, 15 : $514-6$.

7 Laseter JT, Russell JA. Anabolic steroid-induced tendon pathology: a review of the literature. Med Sci Sports Exerc 1991; 23: 1-3.

8 Wood TO, Cooke PH, Goodship AE. The effect of exercise and anabolic steroids on the mechanical properties and crimp morphology of the rat tendon. Am J Sports Med 1988; 16: 153-8.

\title{
Traumatic arteriovenous fistula of the superficial temporal vessels: a case for protective headgear when playing squash?
}

\author{
Simon R Stubington and Keith M Rigg \\ Department of Surgery, Nottingham City Hospital, Hucknall Road, Nottingham, NG5 IPB, UK
}

A 35 year old semiprofessional squash player developed the symptoms and signs of an arteriovenous fistula of the left superficial temporal vessels after a squash ball injury. This was sufficiently symptomatic to halt his intensive

Address for correspondence: Mr S R Stubington FRCS, Department of Surgery, Nottingham City Hospital, Hucknall Road, Nottingham NG5 1PB, UK. training programme and required exploration, ligation and excision. Although a rare injury from any cause this would have been prevented by protective headgear.

(Br J Sports Med 1995; 29: 276-277)

Keywords : arteriovenous fistula, temporal arteries, racquet sports, head protective devices 

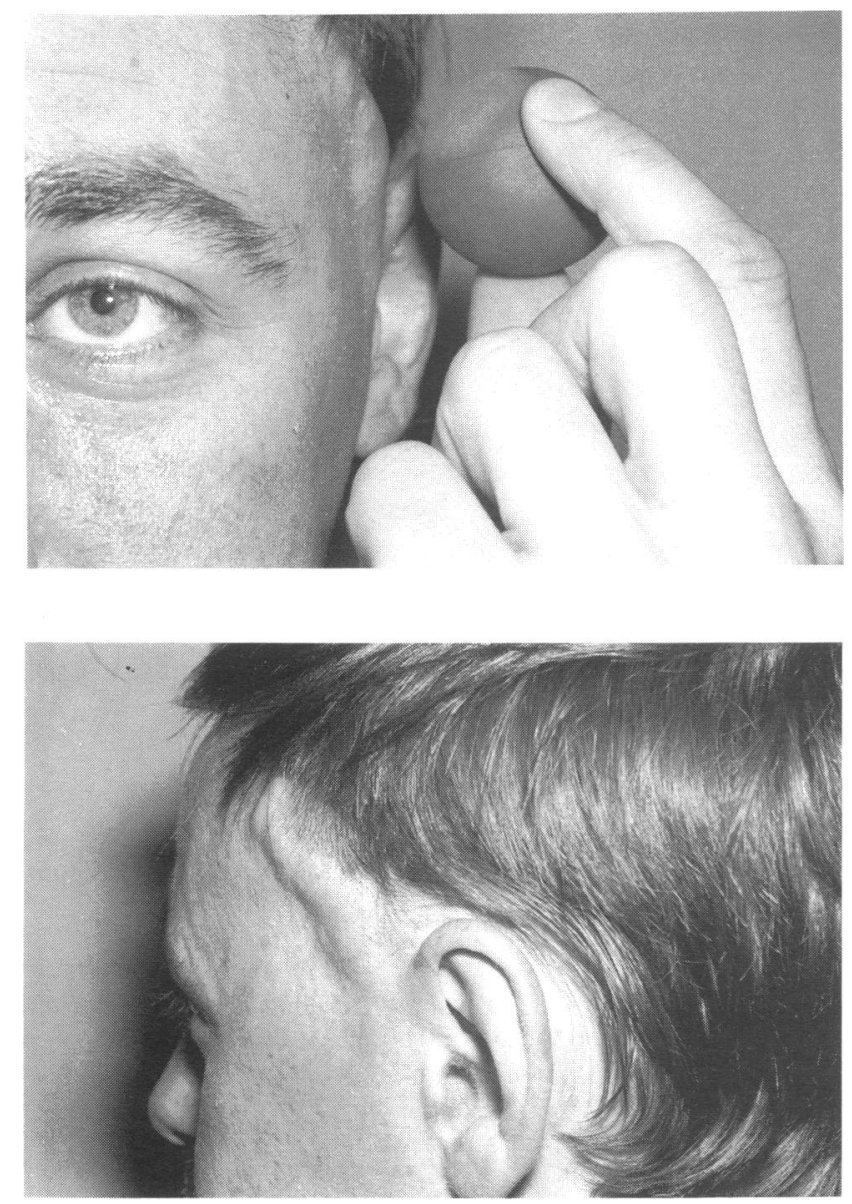

Figure 1. Anterior and lateral views of the dilated tortuous superficial temporal vein fed by an arteriovenous fistula and the causative agent.

\section{Case report}

A 35 year old policeman presented in the general surgical outpatient clinic 12 months after being hit on the left temporal region by a squash ball propelled by a full-blooded forehand. The region had initially been painful and developed a swelling the size of a golf ball with bruising. A series of skull radiographs showed no evidence of a fracture. Two days later he noticed a thumping sensation in his left ear associated with a 'howling noise'. This kept him awake at night, distracted his hearing, and was exacerbated by stress or exercise. Upon resolution of the initial haematoma a tortuous dilated vessel gradually became evident in this region (Figure 1). He curtailed his intensive training programme because the ensuing exacerbation of his symptoms was so distressing.
Examination revealed an $18 \mathrm{~cm}$ visible dilated vessel in the distribution of the anterior branch of the superficial temporal vein with a thrill and a bruit but no other local abnormality. The pulsation disappeared when firm pressure was applied over the root of the superficial temporal artery.

A clinical diagnosis of a traumatic arteriovenous fistula was made and the region was explored under general anaesthesia. The fistula was identified, the vessels ligated, and the fistula excised.

On subsequent review the patient was asymptomatic and had returned to playing squash five times a week.

\section{Discussion}

Traumatic arteriovenous fistulas are rare, although increasingly of iatrogenic origin. ${ }^{1}$ Arteriovenous fistulas of the superficial temporal vessels are particularly rare, and there have been only occasional published reports. ${ }^{2,}{ }^{3}$ However, they do not pose a significant diagnostic problem and providing one can be confident that there is no extracranial-intracranial communication they are simple to deal with by surgical excision.

There have been several communications published recently promoting the adoption of protective eyewear by squash players. ${ }^{4,5}$ Recent years have also seen the introduction of protective headgear to an increasing number of sports and leisure activities, ranging from compulsory helmets for domestic motorcycling through the adoption of helmets in riding, canoeing, cycling, and cricket, to the laudable promotion of cycling helmets for the young rider as a fashion accessory. Is there a case for the introduction of protective headgear into confined court racquet sports as well? The injury reported here would certainly have been prevented by a suitable helmet, which need not be too bulky to provide comfortable but effective protection to the player from injury from racquet, ball, wall, or aggrieved opponent.

\section{References}

1 Schonbach B, Scholasser V. Pathogenesis and changes in the aetiology of arterio-venous fistulae. Eur J Vasc Surg 1990 ; 4 : 233-7.

2 Aranda G, Gonzalez R, Preto R, deGorriz L, Cobhan M, Lombardo $\mathrm{M}$. Arteriovenous fistula of the superficial temporal artery [in Spanish]. Revista Medica De Panama 1991; 16: 211-4.

3 Heher W, Luhn JP. Arteriovenous fistula of the temporal vessels-a rare complication of blunt cranial trauma [German]. HNO 1985; 33 : 332-4.

4 MacEwen CJ, Jones NP. Eye injuries in racquet sports [editorial]. BMJ 1991; 302: 1415-6.

5 Genovese MT, Lenzo NP, Lim RK, Morkel DR, Jamrozik KD. Eye injuries among pennant squash players and their attitudes towards protective eyewear. Med J Aust 1990; 153: 655-8. 